\title{
Effects of trout farms on stream macroinvertebrates: linking farm-scale disturbance to ecological impact
}

\author{
J. Angus Webb* \\ Department of Resource Management and Geography, Building 379, 221 Bouverie Street, The University of Melbourne, \\ 3010 Victoria, Australia
}

\begin{abstract}
Trout farms are a significant component of the Australian aquaculture industry, but there have been no studies on the ecological impacts of Australian trout farms. I analysed biological monitoring data from 5 trout farms in the Goulburn Valley, Victoria, Australia. Using multivariate ordination and a Bayesian hierarchical model, I compared macroinvertebrate assemblages from upstream of the farms to those downstream, and related upstream-downstream differences in invertebrate assemblage condition to 5 farm-scale indices of disturbance. I found clear, but small, ecological impacts of individual farms (i.e. upstream to downstream differences in invertebrates), with between-farm variation in impacts largely explained by the indices of disturbance. The greatest impacts were seen for farms with high production intensity that utilise a high proportion of stream discharge, export a high relative load of nitrogen to the stream and are in areas of good biological condition. Recent research has explored operational and engineering solutions that reduce the downstream ecological impacts of trout farms. Adoption of such practices may help such farms to minimise impacts on streams.
\end{abstract}

KEY WORDS: Rainbow trout - Oncorhynchus mykiss · Macroinvertebrates · Ecological impacts · Trout farm · Australia

\section{INTRODUCTION}

Rainbow trout Oncorhynchus mykiss Walbaum is a major aquaculture species in Europe, Asia and the Americas (Sindilariu 2007, Tello et al. 2010), and there is also a small but important trout farming industry in Australia. Although the Australian freshwater salmonid aquaculture industry is tiny by global standards (1637 t in 2003-04 versus around $400000 \mathrm{t}$ annually in Europe), it is an important component of regional economies through direct employment and earnings, and also through its stimulation of tourism and recreational fisheries (Gavine et al. 2006).

The great bulk of rainbow trout aquaculture in the southern Australian state of Victoria is concentrated in the upper tributaries of the Goulburn River. Farms extract water from the waterways and return effluent downstream. Other major extractions (i.e. for irrigated agriculture) occur well downstream of the farms. Salmonid aquaculture is water intensive, often diverting $50 \%$ or more of the average daily discharge of the waterways along which farms are located. Overall, the Victorian salmonid aquaculture diverted between 390 and $630 \mathrm{Ml} \mathrm{d}^{-1}$ in 2003. The majority of Victorian farms have wastewater treatment facilities (typically settling ponds or constructed wetlands) to improve the water quality of discharged effluent (Gavine et al. 2006).

There are concerns that trout farms may have ecological impacts on the rivers from which they draw water and to which they return wastes (Weston et al. 1996, Tello et al. 2010). The most important return wastes are faeces and uneaten food (Camargo 1992a, Oberdorff \& Porcher 1994, Loch et al. 1996). These wastes can lead to eutrophication of waters (reviewed by Hinshaw \& Fornshall 2002), and are discharged as settleable solids that can affect downstream habitat quality in receiving waters (Oberdorff 
\& Porcher 1994, Rennert 1994, Loch et al. 1996, Selong \& Helfrich 1998). Ecological impacts of trout farms have been well researched in Europe, North America and Africa (reviewed by Tello et al. 2010), but there have been no equivalent studies in Australia. Impacts studied include those upon water quality (Loch et al. 1996, Boaventura et al. 1997, Selong \& Helfrich 1998, Sindilariu et al. 2009), microbial assemblages (Carr \& Goulder 1990a, Boaventura et al. 1997, Brown \& Goulder 1999), primary producers (Carr \& Goulder 1990b, Selong \& Helfrich 1998, Villanueva et al. 2000) and fish (Rasmussen 1986, Oberdorff \& Porcher 1994, Selong \& Helfrich 1998). The most widely studied impact is that upon macroinvertebrate assemblages (Camargo 1992b, 1994, Brown 1996, Loch et al. 1996, Selong \& Helfrich 1998, Kirkagac et al. 2004, Roberts et al. 2009, Sindilariu et al. 2009).

However, very few of the studies above have attempted to relate ecological impacts to environmental or operating characteristics of the farms. Selong \& Helfrich (1998) found periphyton standing crop to be correlated with feed loading rates. Sindilariu et al. (2009) found that significant differences in the macroinvertebrate-based saprobic index were restricted to trout farms with higher production intensities (weight of fish produced per volume of ponds). Oberdorff \& Porcher (1994) developed a fish index of biotic integrity specifically designed to detect effects of trout farms in Brittany, France, and then found that impact was positively related to production level.

One possible reason for the lack of studies relating ecological impacts to environmental conditions is that most standard statistical methods are not suited to simultaneously addressing hypotheses at 2 levels (the farm and among farms). Here, I used a hierarchical Bayesian model (Gelman \& Hill 2007) to simultaneously assess ecological impacts of individual trout farms, and to relate these to environmental conditions. Hierarchical Bayesian models have great flexibility, and hence can address complex study designs and questions (Clark 2005) like the 2-level question posed here. For a non-technical explanation of the mechanics of Bayesian hierarchical models, see Webb et al. (2010), while Gelman et al. (2004) provide a more complete mathematical explanation.

Linking ecological impacts of trout farms (or other aquaculture) to their environmental and operating conditions can inform both pure and applied understanding. In terms of basic ecological understanding, such analyses can operate as experiments and improve our understanding of how the stream biota reacts to different kinds of manipulated disturbances. From a practical point of view, improved understanding of the factors mediating impacts of trout farms will facilitate the continued development of operating procedures (MacMillan et al. 2003) and impact abatement technologies (Sindilariu 2007) that can reduce such impacts.

This paper is the first published study of the ecological impacts of trout farms in Australia. I examined impacts on macroinvertebrate assemblages upstream and downstream of 5 farms in the Goulburn Valley, Victoria. To explore potential causal mechanisms for the observed effects, I related them to 5 farm-scale indices of environmental and operating conditions.

\section{MATERIALS AND METHODS}

\section{Area and site characteristics}

The Goulburn Catchment is located in south-eastern Australia in the state of Victoria. While the lowland regions of the catchment are heavily developed for agriculture, the upper areas ( $30 \%)$ of the catchment are still largely forested (Hart et al. 2003). The Goulburn River is the largest tributary to the River Murray in the state of Victoria, and flows north-west from the Great Dividing Range. The region has a temperate climate, and the upper areas of the catchment average $1650 \mathrm{~mm}$ of rainfall annually (BOM 1994)

The great bulk of Victoria's rainbow trout aquaculture industry is concentrated in the upper tributaries of the Goulburn River (Gavine et al. 2006). Data were collected from 5 farms in this area as part of a Victorian Department of Primary Industries study designed to investigate the ecological impacts of trout farms. The farms were chosen on the basis that (1) they were operating according to industry best practice guidelines (Gavine et al. 2006), (2) the selection enabled the identification of individual farm-scale characteristics related to environmental and operating conditions, and (3) they were located in areas of differing stream ecological condition (F. Gavine pers. comm.). From these data, 5 farm-scale indices of environmental and operating conditions-hereafter referred to as 'indices of disturbance' - were chosen. Each index had a plausible, albeit speculative, hypothesis linking it to any ecological impacts (Table 1). Along with the values for the indices of disturbance, other selected environmental and operating characteristics of the farms are supplied in Table 2. To aid interpretation of the univariate statistical 
Table 1. Farm-scale indices of disturbance tested, along with the postulated causal mechanism that could lead to changes in invertebrate assemblages

\begin{tabular}{|c|c|c|}
\hline Impact $(I)$ & Definition & Hypothesis \\
\hline Avg. Ext. & $\begin{array}{l}\text { Average percentage of river dis- } \\
\text { charge extracted from the stream by } \\
\text { the farm }(2006)\end{array}$ & $\begin{array}{l}\text { Removal of a greater proportion of the discharge of a stream reach for } \\
\text { use by the fish farm entails that a correspondingly larger proportion of } \\
\text { the total discharge downstream of the farm will be returned as efflu- } \\
\text { ent. Thus, there may be greater impacts of toxicants or settleable solids. }\end{array}$ \\
\hline FCR & $\begin{array}{l}\text { Food conversion ratio: ratio of } \\
\text { weights of fish produced to food } \\
\text { consumed (2002-2006) }\end{array}$ & $\begin{array}{l}\text { A more efficient fish farm (higher FCR) may have less effect on } \\
\text { resident macroinvertebrates because of the export of smaller amounts } \\
\text { of wasted food in effluent. }\end{array}$ \\
\hline N loading & $\begin{array}{l}\text { Nitrogen loading: total nitrogen } \\
\text { exported from the farm (2005-2006) } \\
\text { / average yearly river discharge }\end{array}$ & $\begin{array}{l}\text { Nutrients exported by the farms can be expected to affect biological } \\
\text { processes in receiving waters, potentially altering food webs and the } \\
\text { resulting invertebrate assemblages. Higher loads relative to stream } \\
\text { size may lead to greater effects. }\end{array}$ \\
\hline Prod. Int. & $\begin{array}{l}\text { Production intensity: fish produced / } \\
\text { volume of ponds and raceways } \\
(2002-2006)\end{array}$ & $\begin{array}{l}\text { More intensive production may lead to higher concentrations of waste } \\
\text { products in returned effluent. This could be expected to lead to greater } \\
\text { effects on macroinvertebrates. }\end{array}$ \\
\hline ISC score & $\begin{array}{l}\text { Index of stream condition (Ladson et } \\
\text { al. 1999), an index of stream health } \\
\text { calculated at the reach }(\sim 10-40 \mathrm{~km}) \\
\text { scale that integrates hydrology, } \\
\text { geomorphology, vegetation, water } \\
\text { quality and invertebrates }\end{array}$ & $\begin{array}{l}\text { This is not an index of disturbance per se, and is not directly related to } \\
\text { aquaculture, but is an integrative assessment of overall ecological } \\
\text { condition. However, it is reasonable to hypothesize that farms located } \\
\text { in areas of good condition may have greater impacts. Sensitive families } \\
\text { in high-quality (higher ISC score) reaches might be greatly affected by } \\
\text { the presence of fish farms. In poorer-quality reaches (lower score), an } \\
\text { already depauperate assemblage may be less affected. }\end{array}$ \\
\hline
\end{tabular}

results, I calculated Pearson correlation coefficients among the indices of disturbance.

\section{Biological monitoring data}

Macroinvertebrate data were collected between 2005 and 2007. At each farm, 2 sites were established upstream of the effluent outfall, a third site was established immediately downstream of the outfall, and 2 further sites were established between 130 and $350 \mathrm{~m}$ farther downstream. The upstream sites were assumed to represent controls for any downstream impacts caused by the trout farms, but were not assumed to be in pristine condition (i.e. they were not reference sites). Each site was sampled 3 or 4 times over a period of 3 to 4 mo designed to coincide with the greatest potential impact of the adjacent trout farm (i.e. during periods of lowest flow). Sampling followed a rapid bioassessment protocol commonly used for environmental condition reporting in Victoria (EPA Victoria 2003). Briefly, riffle habitats were sampled using the kick sampling method (Storey et al. 1991). Samples were collected over $10 \mathrm{~m}$ of stream bed, followed by live picking of the sample with the naked eye for $30 \mathrm{~min}$. Invertebrates collected were identified to family level and counted.
Table 2. Trout farm characteristics. Stream discharge: average daily discharge for the receiving stream for the year 2006; farm size: total volume of ponds and raceways; annual production: average for 2002 to 2006. Definitions and abbreviations for the farm-scale indices of disturbance are presented in Table 1

\begin{tabular}{|c|c|c|c|c|c|c|c|c|}
\hline Farm & $\begin{array}{c}\text { Stream } \\
\text { discharge } \\
\left(\mathrm{Ml} \mathrm{d}^{-1}\right)\end{array}$ & $\begin{array}{l}\text { Farm } \\
\text { size } \\
\left(\mathrm{m}^{3}\right)\end{array}$ & $\begin{array}{l}\text { Annual } \\
\text { produc- } \\
\text { tion }(\mathrm{t})\end{array}$ & $\begin{array}{l}\text { Farm } \\
\text { Avg. Ext. } \\
(\%)\end{array}$ & $\begin{array}{l}\text {-scale } \\
\text { FCR }\end{array}$ & $\begin{array}{l}\text { indices of } \\
\mathrm{N} \text { loading } \\
\left(\mathrm{kg} \mathrm{Ml}^{-1}\right)\end{array}$ & $\begin{array}{c}\text { disturbance } \\
\text { Prod. Int. } \\
\left(\mathrm{t} \mathrm{m}^{-3}\right)\end{array}$ & $\begin{array}{l}\text { e } \\
\text { ISC } \\
\text { score }\end{array}$ \\
\hline A & 75 & 13293 & 93 & 51 & 1.3 & 0.271 & 0.009 & 29 \\
\hline B & 39 & 2910 & 92 & 49 & 1.095 & 0.340 & 0.032 & 36 \\
\hline C & 33 & 2278 & 67 & 81 & 1.225 & 0.294 & 0.029 & 42 \\
\hline D & 214 & 13400 & 80 & 52 & 1.3 & 0.126 & 0.006 & 28 \\
\hline E & 3606 & 41400 & 357 & 8.8 & 1.09 & 0.013 & 0.009 & 16 \\
\hline
\end{tabular}

\section{Statistical analyses}

Multivariate analysis

I examined multivariate patterns in the data using non-metric multidimensional scaling (MDS; Kruskal $\&$ Wish 1978). Family-level abundances were square-root transformed to reduce the impact on the analysis of the most abundant taxa. Bray-Curtis similarities (Bray \& Curtis 1957) were used to describe 
the multivariate distance between all pairs of samples. Analyses were conducted using Primer V5 (Clarke \& Gorley 2001).

\section{Univariate analysis}

Two dependent variables were used in the univariate analyses of ecological impacts: the biotic index SIGNAL (Chessman 1995), and the richness of Ephemeroptera, Plecoptera and Trichoptera (EPT) families. SIGNAL assigns ratings from 1 to 10 to macroinvertebrate families found at a site, with 1 indicating a pollution-tolerant family, and 10 indicating a highly pollution-sensitive family. The SIGNAL score of a site is simply the average of the ratings of all the families present at a site. SIGNAL has previously been used successfully to detect fine-scale changes in ecological condition using Bayesian models (Webb \& King 2009). A site in good condition is expected to have a SIGNAL score of 6 or more, while a score of less than 4 indicates probable severe pollution (Chessman 1995). EPT taxa are generally accepted to be sensitive to environmental disturbance (Rosenberg \& Resh 1993), and the taxa richness of this group has previously been employed in studies of the ecological impacts of trout farms (Loch et al. 1996, Roberts et al. 2009).

The hierarchical Bayesian model calculated the temporal average of SIGNAL or EPT score-hereafter referred to collectively as 'condition' — at each site, before averaging among upstream (Sites 1 and 2) and downstream (Sites 3 to 5) sites for each farm. It should be noted that all uncertainties (temporal within sites, spatial within upstream and downstream areas) are propagated through the model. The difference between upstream and downstream average condition was then related to each farmscale index of disturbance in separate analyses. More specifically, I formulated the model as follows. Each temporally replicated $(k)$ data point $\left(y_{i j k}\right)$ was modelled as a normally distributed $(N)$ variable, with a mean $(\mu)$ for each site $(j)$ within each farm $(i)$, with a common temporal variance $\left(\delta^{2}\right)$ across all sites.

$$
y_{i j k} \sim N\left(\mu_{i j}, \sigma_{\mathrm{T}}^{2}\right)
$$

Site-level average condition was assumed to be drawn from a distribution of possible site averages either upstream $\left(\mu_{U}\right)$ or downstream $\left(\mu_{D}\right)$ of the effluent outlet for each farm, with a common longitudinal variance $\left(\sigma_{L}^{2}\right)$ across all farms.

$$
\begin{gathered}
\mu_{i, j \in\{1,2\}} \sim N\left(\mu_{\mathrm{U} i}, \sigma_{\mathrm{L}}^{2}\right) \\
\mu_{i, j \in\{3,4,5\}} \sim N\left(\mu_{\mathrm{D} i}, \sigma_{\mathrm{L}}^{2}\right)
\end{gathered}
$$

The difference between upstream and downstream condition $\left(\delta_{\mathrm{UD}}\right)$ is the variable of primary interest and is modelled as a function of the index of disturbance. Because one cannot also simultaneously define $\delta_{\mathrm{UD}}$ as the difference between $\mu_{\mathrm{U}}$ and $\mu_{\mathrm{D}}$, I instead used

$$
\mu_{\mathrm{D} i}=\mu_{\mathrm{U} i}-\delta_{\mathrm{UD} i}
$$

with $\mu_{\mathrm{U}}$ being assigned a minimally informative prior distribution $N\left(0,100^{2}\right)$ and $\delta_{\text {UD }}$ being defined as a linear function of each of the indices of disturbance. I also confirmed that the alternate expression of Eq. (3) $\left(\mu_{\mathrm{U} i}=\mu_{\mathrm{D} i}+\delta_{\mathrm{UD} i}\right)$ made no difference to the results obtained. Because only 5 farms were included in the analysis, commonly used minimally-informative priors for variance parameters at this level of the model (e.g. the inverse Gamma distribution) can have noticeable effects on the posterior distributions (Gelman 2006). I used a half-Cauchy prior distribution to minimise this effect (Gelman 2006). Namely, $\delta_{\text {UD }}$ and its associated variance was modelled as

$$
\begin{gathered}
\delta_{\mathrm{UDi}}=\mu_{\mathrm{UD} i}+\zeta \cdot \eta_{i} \\
\mu_{\mathrm{UD} i}=\alpha+\beta \cdot I_{i} \\
\zeta \sim N\left(0, A^{2}\right) \\
\eta_{i} \sim N\left(0, \sigma_{\eta}^{2}\right) \\
\sigma_{\delta}=|\zeta| \cdot \sigma_{\eta}
\end{gathered}
$$

where $\mu_{\mathrm{UD}}$ is the fitted value of a linear function of the index of disturbance $(I)$ defined with intercept $\alpha$ and slope $\beta$, and the terms $\zeta$ and $\eta$ dictate the deviation of individual $\delta_{\mathrm{UD}}$ values from $\mu_{\mathrm{UD}}$. $A$ is the scale parameter of the half-Cauchy distribution and is the median of the prior standard deviation around $\mu_{\mathrm{UD}}$. This figure should be set at a level higher than expected for the final estimate (Gelman 2006). Other prior distributions were assigned as follows: $\alpha, \beta$ $N\left(0,100^{2}\right) ; \sigma_{\mathrm{T}}, \sigma_{\mathrm{L}} \sim U[0,100]$; and following Gelman (2006) $1 / \sigma_{\eta}^{2} \sim \Gamma(0.5,0.5)$, where $U$ and $\Gamma$ denote the Uniform and Gamma distributions, respectively. The hierarchical structure of the model is illustrated in Fig. 1.

The Bayesian model was implemented in WinBUGS 1.4.3 (Lunn et al. 2000). I used 3 parallel Markov chains for estimation. Each chain was burned in for 10000 iterations, with a further 50000 iterations for parameter estimation. The Brooks Gelman Rubin diagnostic (Brooks \& Gelman 1998) was used to check convergence of the chains. To reduce autocorrelation in the Markov chains, I applied a post hoc thinning of the chains of 1 in 5 values (i.e. 4 out of every 5 values were discarded). These various operations resulted in a total sample size for parameter estimation of 30000 . I used the 'step' function to test the hypotheses that $\delta_{\mathrm{UD}}$ for each farm was $>0$, and 


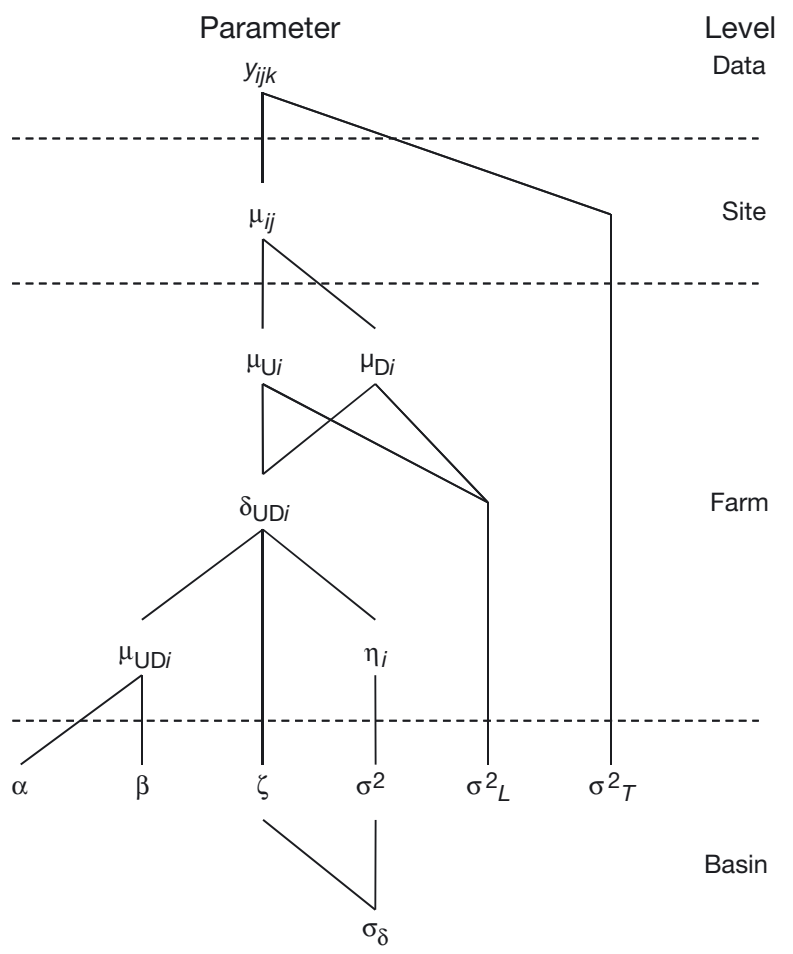

Fig. 1. Hierarchical structure of the Bayesian statistical model. See 'Materials and methods' for definitions of parameters

also that $\delta_{\mathrm{UD}}$ was correlated with $I$ (i.e. slope of line $\beta$ differed from 0 ), with the effect of each index of disturbance being assessed separately. The WinBUGS code for this model is available in the supplement at www.int-res.com/articles/suppl/q003p023_supp/.

\section{RESULTS}

\section{Multivariate analysis}

The assemblage level data from 1 farm were very different from all others, resulting in an MDS plot dominated by this difference (not shown). To better visualise between and within-farm patterns, I re-ran the analysis with the data from the outlying farm removed (Fig. 2).

The stress level of the resulting plot is quite high (0.23), indicating that fine-scale structure of the plot may not be a good representation of the multivariate pattern (Clarke 1993). However, the broad-scale patterns are quite clear. The plot shows clear separation among the farms, mostly moving from the bottom left to the top right of the plot. It also shows clear differences between upstream and downstream samples, moving from the top left of the plot to the bottom right. This indicates that qualitatively similar differ-

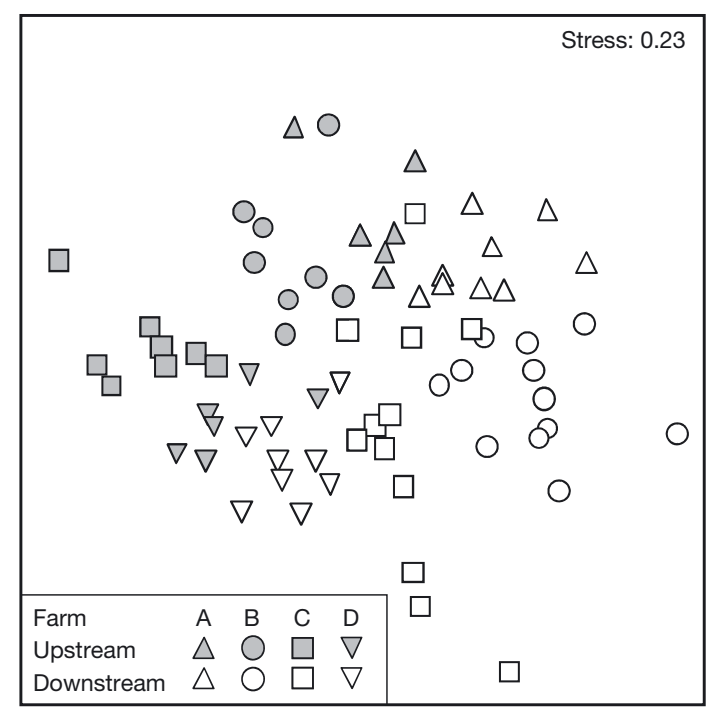

Fig. 2. Multidimensional scaling plot of the sample data. Different symbols depict samples taken around 4 different farms (A to D). Filled (empty) symbols denote samples taken from upstream (downstream) of the farm (A to D)

ences in condition are occurring between upstream and downstream sites at the different farms. Also noticeable among the farms is a substantial difference in the within-farm variability (e.g. Farm C vs. Farm D), and in the size of the upstream-downstream difference in condition (e.g. Farm A vs. Farm B).

\section{Univariate analysis}

There were significant correlations among 3 of the 5 indices of disturbance (Table 3). The index of stream condition (ISC) score was positively correlated with average $\%$ of discharge extraction of water and nitrogen loading, but these latter 2 variables were not significantly correlated.

The Bayesian models showed strong effects of the individual farms. Each model produced different estimates of the upstream-downstream differences for individual farms (Fig. 3). This arises because

Table 3. Pearson correlation coefficients among the farmscale indices of disturbance (Table 1). Sample size $=5$ for all correlations. ${ }^{*}$ Significant at $\mathrm{p}<0.05$ ( $t$-test)

\begin{tabular}{|c|c|c|c|c|}
\hline & Avg. Ext. & Food Conv. & $\mathrm{N}$ loading & Prod. Int \\
\hline Food Conv. & 0.53 & & & \\
\hline N loading & 0.75 & 0.14 & & \\
\hline Prod. Int. & 0.52 & -0.44 & 0.74 & \\
\hline ISC score & $0.93^{*}$ & 0.22 & $0.88^{*}$ & 0.78 \\
\hline
\end{tabular}



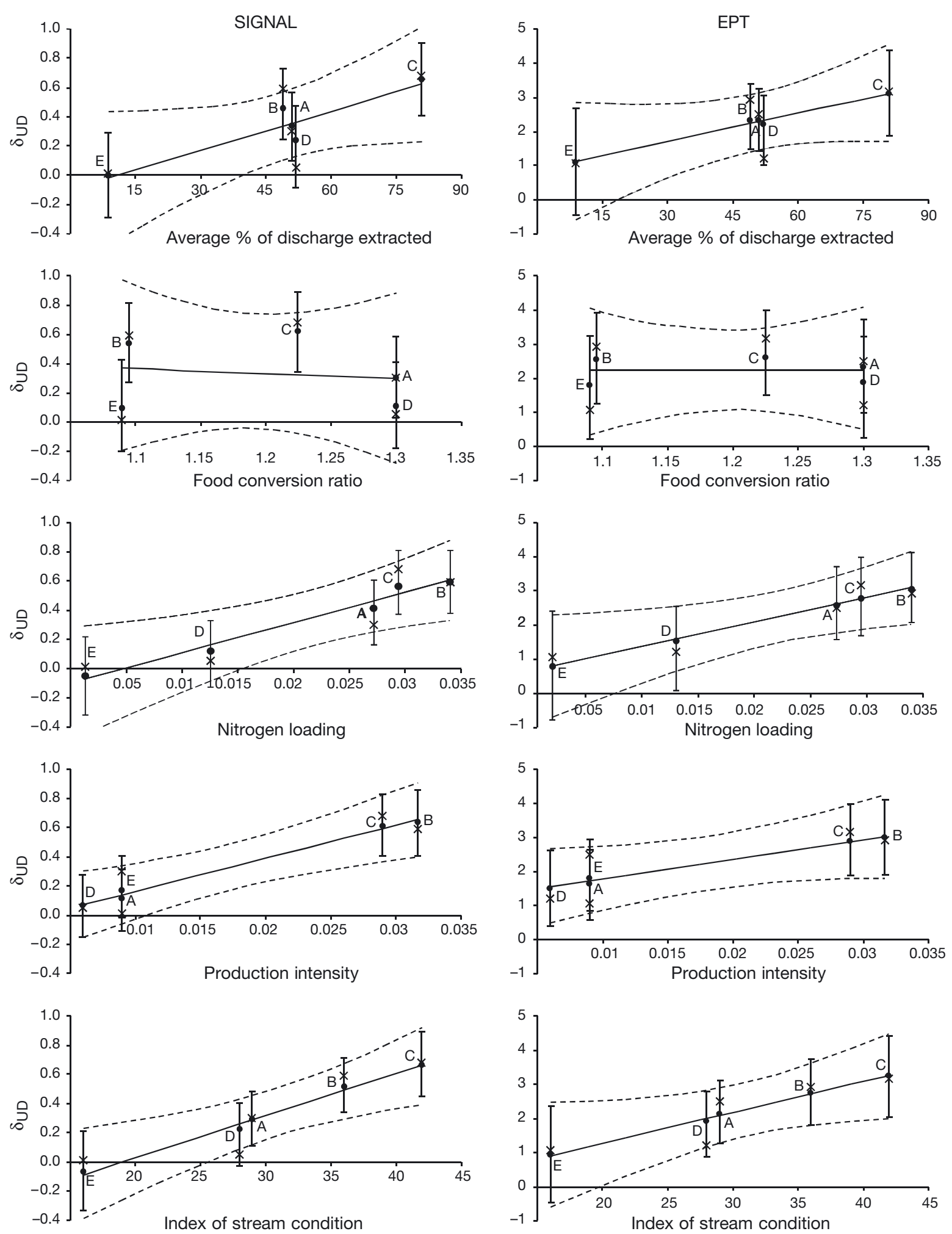

Fig. 3. Ecological impacts (differences in condition from upstream to downstream, $\delta_{\text {UD }}$ ) expressed as a function of the farmscale indices of disturbance. Graphs in the left column are those for SIGNAL score data; those in the right column are for Ephemeroptera, Plecoptera and Trichoptera (EPT) taxa counts. Filled circles are the median modelled $\delta_{\text {UD }}$ values for each farm (marked by letters A-E), with the error bars encompassing the 95\% credible interval for the parameter estimate. Crosses are the mean measured upstream to downstream difference in ecological condition. Solid line is the median estimate for the linear function relating $\delta_{\mathrm{UD}}$ to farm-scale indices of disturbance, with the dashed lines encompassing the $95 \%$ credible interval for 
these differences are not only modelled using the data from that farm, but also have the prior estimate of upstream-downstream difference informed by the data from the other farms and the way they are related via the relationship with the index of disturbance (Webb et al. 2010). The difference between the median modelled value of $\delta_{\text {UD }}$ and the average observed difference gives an indication of how well the models fit the data (Fig. 3). The average probability among the different models for each farm provides an ensemble measure of farm-scale impacts. Probabilities represent level of support for the hypothesis and are interpreted differently to frequentist null-hypothesis $\mathrm{p}$ values. A probability near 1 indicates support for the hypothesis that upstream ecological condition is better than downstream condition (i.e. $U>$ D), while a value near 0 indicates support for the opposite (not the null) hypothesis. Values near 0.5 indicate no support in either direction (the null hypothesis). For Farms A, B and C, probabilities of a decrease in condition downstream of the effluent outlet were all very close to 1 for both SIGNAL scores and EPT counts ( $\mathrm{p}=0.99$ or greater), indicating virtual certainty of the hypothesis. For Farms D and E, probabilities of a reduction in EPT taxa richness were still very high $(p>0.99$ and $p=0.94$, respectively), but reduction in the SIGNAL score was less pronounced for Farm D ( $p=0.86)$, and there was no evidence of a difference for Farm E $(p=0.55)$.

Among farms, there were consistent results for SIGNAL and EPT data, with SIGNAL proving slightly more sensitive in detecting relationships between ecological impacts and indices of disturbance (comparison of probabilities in Table 4). Reductions in macroinvertebrate assemblage condition were strongly positively associated with average $\%$ of discharge extracted from the stream, nitrogen loading, production intensity, and ISC score. There was no evidence of an association between either SIGNAL or EPT and food conversion ratio (Table 4, Fig. 3).

Table 4. Results of basin-scale hypothesis tests, showing the probabilities that upstream-downstream reductions in ecological condition (i.e. ecological impacts) are positively related to the farm-scale indices of disturbance (Table 1). Parameters are defined in 'Materials and methods'. SIGNAL and EPT denote analyses of SIGNAL scores and Ephemeroptera, Plecoptera and Trichoptera (EPT) taxa counts, respectively

\begin{tabular}{|lccccc|}
\hline Variable & \multicolumn{5}{c|}{ Index of disturbance } \\
& Avg. Ext. & FCR & N loading & Prod. Int. ISC score \\
\hline SIGNAL & 0.97 & 0.41 & 0.99 & $>0.99$ & $>0.99$ \\
EPT & 0.94 & 0.50 & 0.98 & 0.95 & 0.97 \\
\hline
\end{tabular}

\section{DISCUSSION}

\section{Ecological impacts of trout farms}

The analyses clearly detected impacts of the trout farms on downstream macroinvertebrate assemblages. Findings therefore mirror those from elsewhere in the world (Camargo 1992b, 1994, Brown 1996, Loch et al. 1996, Selong \& Helfrich 1998, Roberts et al. 2009, Sindilariu et al. 2009). However, it should be noted that these effects were not large. Differences in SIGNAL scores were no larger than $\sim 0.6$, which is close to the background uncertainty inherent in the determination of SIGNAL (Metzeling et al. 2004). Differences in number of EPT taxa were no larger than $\sim 3$, and were generally around $20 \%$ of the taxa richness of the upstream site (results not shown). Moreover, the downstream (i.e. most impacted) values for both SIGNAL and EPT scores were above the minimum biological objectives set for this region (SIGNAL $\geq$ 6.0, EPT $\geq 9$; Metzeling et al. 2004) for Farms A to $D_{\text {; }}$ and while Farm E fell just short of its regional objective (SIGNAL $\geq 5.5$ ), this was not caused by any effect of the farm itself, as the upstream SIGNAL score also did not meet the objective (results not shown). It should also be remembered that the downstream sites were relatively close to the effluent outfall (maximum of $350 \mathrm{~m}$ ) where impacts should be maximised. Those sites would not be representative of ecological conditions at larger scales, and indeed previous research has found that the major impacts of trout farm effluent discharges are generally localised to areas hundreds of metres from the outfall (Loch et al. 1996, Selong \& Helfrich 1998).

I was able to identify statistical associations between reductions in ecological condition and 4 of the 5 farm-scale indices of disturbance. There are also plausible conceptual models for causal linkages between these variables (Table 1). However, the relationships detected are not necessarily causal. Experimental research would be required to more confidently identify which of the statistical relationships identified in this study are causal linkages.

In terms of pure statistical fit of the models, the relationship of change in ecological condition to nitrogen loading is the most convincing. For this model, median modelled $\delta_{\mathrm{UD}}$ is close to the measured value for all farms. The intermediate values for nitrogen loading (Farms D, A, C) are also well distributed between the low and high values, providing a 'dose-response' relationship between $\delta_{\mathrm{UD}}$ and nitrogen loading. The other models lack 1 or more of these characteristics. The model for the ISC score does a poor job of model- 
ling the $\delta_{\mathrm{UD}}$ value for Farm D, with the measured value near the lower end of the $95 \%$ credible interval of the modelled parameter. The relationship between ecological condition and average \% of discharge extracted is caused entirely by the observations for Farms C and E. Finally, there are no intermediate values of production intensity, which means we cannot describe a dose-response relationship between ecological impact and production intensity (Fig. 3).

Nevertheless, the relationship between magnitude of ecological impact and production intensity of the farms is not only consistent with the postulated conceptual model, it is also consistent with the small amount of previous research that exists on this topic (Selong \& Helfrich 1998, Sindilariu et al. 2009). It suggests that reducing production intensity would ameliorate ecological impacts. In contrast, the lack of any relationship between food conversion ratio and ecological impact (the lines of best fit are almost horizontal; Fig. 3) suggests that there is no environmental argument for improving feeding efficiency in these farms.

The colinearity of the ISC score with nitrogen loading and with average \% of discharge extracted means that it is more difficult to interpret these effects. The results are all consistent with the conceptual models (Table 1). It is reasonable to expect that assemblages in better condition upstream (high ISC score), and therefore containing sensitive species, would experience greater ecological impacts than assemblages from which sensitive species have already been lost. It is equally reasonable to hypothesize that having a higher proportion of effluent in downstream discharge (average \% of discharge extracted) would lead to higher relative loads of settleable solids and higher nutrient levels (nitrogen loading) in receiving waters, and therefore greater impacts upon macroinvertebrates. A greater proportion of discharge is extracted, and higher nitrogen loadings are delivered by farms on smaller streams. The smaller streams are also in better condition at the reach scale (ISC score) than the larger streams (Table 2). The current results, therefore, do not allow us to disentangle the separate impacts of these 3 indices of disturbance. The effects could be isolated if one could locate farms where the ISC score was not correlated with either average \% of discharge extracted or nitrogen loading, but this may not be possible, especially within a small aquaculture industry like that of Australia.

The ISC score is not fully independent of either SIGNAL or EPT because macroinvertebrate assemblage condition is 1 component of the overall index. Therefore, I expect to see higher SIGNAL and EPT scores in streams with higher ISC scores. The results for ISC score (Fig. 3) leave open the possibility that fish farms are reducing macroinvertebrate condition to a uniform level, and that the relationship between ISC score and both SIGNAL and EPT is simply a function of a relationship between ISC and upstream values of SIGNAL and EPT. However, this is not the case, and although the assemblages from the highest-quality sites are being more impacted by trout farms, downstream scores still vary greatly among the farms (Fig. 4).

Production intensity, average \% of discharge extracted, nitrogen loading and food conversion ratio can be improved by changing operating procedures (MacMillan et al. 2003), and may also respond to engineering solutions designed to reduce off-farm impacts (Sindilariu 2007). However, any intrinsic effects of local environment quality (ISC score) cannot be addressed short of decommissioning farms in pristine areas. Unfortunately, such areas often offer
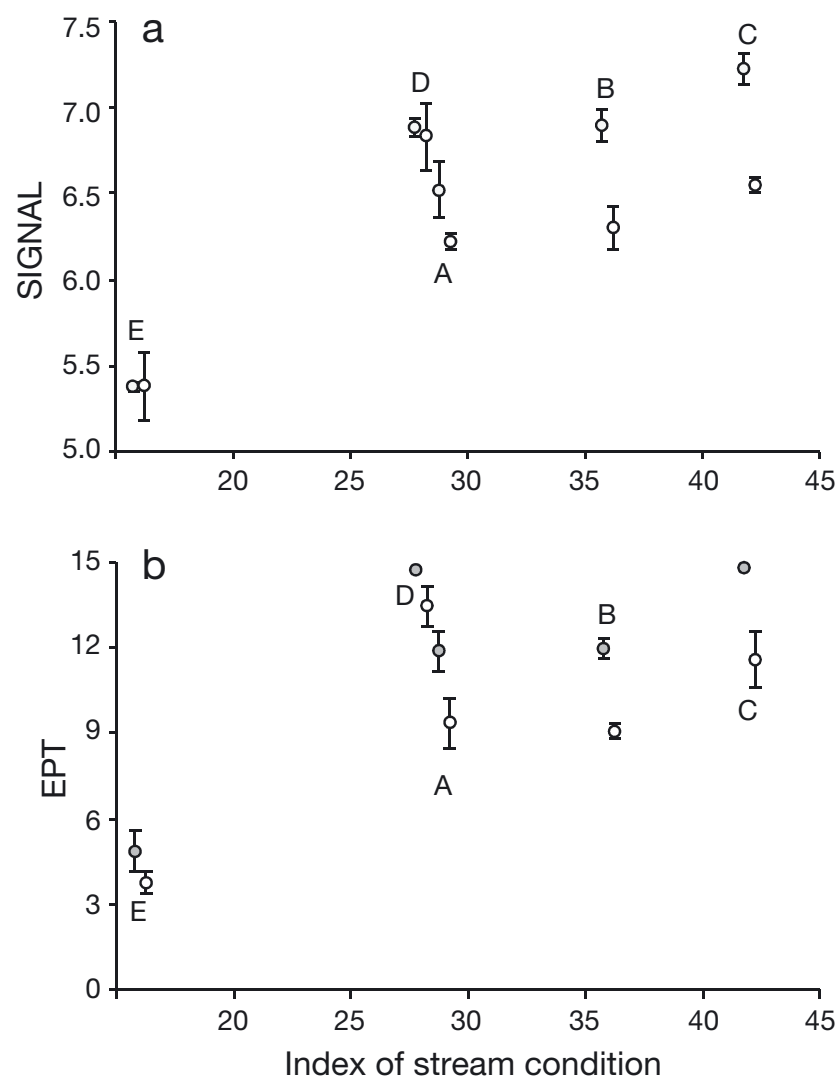

Fig. 4. Ecological condition versus reach-scale index of stream condition (ISC) score. Filled symbols are average upstream (a) SIGNAL scores or (b) Ephemeroptera, Plecoptera and Trichoptera (EPT) taxa counts for the upper and lower panels, respectively, with empty symbols being the downstream averages (both \pm SD across sites) for each farm (marked by letters A-E). $X$-axis is the reach-scale ISC score as used in the univariate analysis. Upstream and downstream averages for the same farm are slightly offset on the $x$-axis to facilitate comparison 
the best conditions for rainbow trout aquaculture (Tello et al. 2010), which is why many farms are found in otherwise undeveloped areas (e.g. Boaventura et al. 1997). Moreover, recent research has also shown that measurable ecological impacts can still be observed some years after decommissioning farms (Hurd et al. 2008), reducing the value of such actions.

\section{Analytical techniques}

Given the small sizes of ecological impacts noted above, the definitiveness of the results (i.e. most hypothesis test probabilities close to 1.0) appears to be at least partly a function of the chosen metrics of macroinvertebrate condition and the analytical technique used. The 2 metrics quantify different properties of the macroinvertebrate assemblage, with SIGNAL taking all taxa and their relative sensitivity to disturbance into account, and EPT being a simple taxon count of a portion of the overall assemblage. The different results for Farms D and E for the 2 metrics show the value of testing multiple endpoints, and demonstrate that sensitive families were being lost from these sites, despite the small differences in SIGNAL score. Overall, the 2 metrics produced highly consistent results (Fig. 3), which increases confidence in the conclusions. EPT has previously been successfully used to infer effects of trout farms on downstream macroinvertebrate assemblages (Loch et al. 1996, Roberts et al. 2009), and this study shows that SIGNAL is also a sensitive indicator of such impacts.

The initial exploratory MDS, based on the full species abundance matrix, showed clear separation of the upstream and downstream sites, and demonstrated that the same kinds of ecological impacts were being experienced at different farms. However, it also showed that the magnitude of these impacts varied among farms. The hierarchical Bayesian model then allowed formal testing for ecological impacts, while at the same time testing for different plausible relationships between these impacts and indices of disturbance. Although one of the often-cited advantages of Bayesian analysis is the ability to incorporate prior information, little information exists in this case. More important for this analysis was the ability of Bayesian methods to build a flexible model, in this case one that could simultaneously test hypotheses at 2 levels (farm-scale ecological impacts and relationships of these impacts to indices of disturbance). I believe this analytical approach to be a more satisfactory way of testing for such relationships than has been used in past studies of the ecological impacts of trout farms. These have variously involved: visual matching of impacts to production intensity (Sindilariu et al. 2009), '2-stage' analysis where the results of a principal components analysis were regressed against production figures (Oberdorff \& Porcher 1994) or analysing the results of downstream stations only (Selong \& Helfrich 1998). Furthermore, it would also be possible to use the parameterized Bayesian models to produce quantitative estimates (with uncertainties) of predicted ecological impacts of other farms for which the indices of disturbance were available, or for 'gaming' the likely benefits of changes in management practice (i.e. changes in the indices of disturbance; sensu Webb et al. 2010).

\section{CONCLUSIONS}

I have shown that the farms studied have detectable impacts on downstream macroinvertebrate assemblage condition. However, the impacts detected in this study were not severe. Effects on native fish assemblages (Oberdorff \& Porcher 1994), primary production (Carr \& Goulder 1990b) and microbial processes (Brown \& Goulder 1999) are at this time unknown. The clarity with which the analyses detected these impacts appears to be partly due to the sensitivity of the hierarchical Bayesian approach, supporting its use in further similar assessments. Strong relationships of ecological impact with the average percentage of discharge extracted from the river, with the nitrogen loading delivered to the stream and with upstream ecological condition, are confounded and cannot be interpreted with confidence using the current data set. However, an equally strong relationship of ecological impact with production intensity suggests a course of management action to ameliorate impacts.

Acknowledgements. I thank the Victorian Department of Primary industries, and in particular F. Gavine, for providing access to the data set used in this paper and for allowing the use of some findings from a previous consultancy contract. Thank you also to M. Padgham and 4 anonymous reviewers for reviewing and improving earlier versions of the manuscript.

\section{LITERATURE CITED}

Boaventura R, Pedro AM, Coimbra J, Lencastre E (1997) Trout farm effluents: characterization and impact on the receiving streams. Environ Pollut 95:379-387

BOM (Bureau of Meteorology) (1994) Climate statistics for Australian locations: Summary statistics Rubicon SEC Available at www.bom.gov.au/climate/averages/tables/ Cw_088068.shtml (accessed on 21 October, 2012)

Bray JR, Curtis JT (1957) An ordination of the upland forest com- 
munities of southern Wisconsin. Ecol Monogr 27:325-349

Brooks SP, Gelman A (1998) General methods for monitoring convergence of iterative solutions. J Comput Graph Statist 7:434-455

Brown CA (1996) Macroinvertebrate community patterns in relation to physico-chemical parameters measured at two land-based trout farms affecting streams in the southwestern cape, South Africa. Arch Hydrobiol 138:57-76

Brown SE, Goulder R (1999) Change in riverine epilithic extracellular enzyme activity in response to fish farm effluent. Lett Appl Microbiol 29:385-388

Camargo JA (1992a) Structural and trophic alterations in macrobenthic communities downstream from a fish farm outlet. Hydrobiologia 242:41-49

Camargo JA (1992b) Temporal and spatial variations in dominance, diversity and biotic indexes along a limestone stream receiving a trout farm effluent. Water Air Soil Pollut 63:343-359

Camargo JA (1994) The importance of biological monitoring for the ecological risk assessment of freshwater pollution-a case study. Environ Int 20:229-238

Carr OJ, Goulder R (1990a) Fish-farm effluents in rivers. 1. Effects on bacterial populations and alkaline phosphatase activity. Water Res 24:631-638

> Carr OJ, Goulder R (1990b) Fish-farm effluents in rivers. 2. Effects on inorganic nutrients, algae and the macrophyte Ranunculus penicillatus. Water Res 24:639-647

Chessman BC (1995) Rapid assessment of rivers using macroinvertebrates: a procedure based on habitatspecific sampling, family-level identification and a biotic index. Aust J Ecol 20:122-129

Clark JS (2005) Why environmental scientists are becoming Bayesians. Ecol Lett 8:2-14

> Clarke KR (1993) Non-parametric multivariate analyses of changes in community structure. Aust J Ecol 18:117-143

Clarke KR, Gorley RN (2001) Primer v5: user manual/tutorial. PRIMER-E, Plymouth

EPA (Environment Protection Authority) Victoria (2003) Guideline for environmental management: rapid bioassessment methodology for rivers and streams. Publication 604.1, Environment Protection Authority Victoria, Melbourne. Available at http://tinyurl.com/3wldbo

Gavine F, Larkin B, Ingram B, Edwards M (2006) Best practice environmental management guidelines for the salmonid aquaculture industry. Department of Primary Industries, Melbourne. Available at http://tinyurl.com/ Aquculture-BMPs (accessed on 1 September 2012)

Gelman A (2006) Prior distributions for variance parameters in hierarchical models (comment on article by Browne and Draper). Bayesian Anal 1:515-534

Gelman A, Hill J (2007) Data analysis using regression and multilevel/hierarchical models. Cambridge University Press, Cambridge

Gelman A, Rubin JB, Stern HS, Rubin DB (2004) Bayesian data analysis. Chapman \& Hall/CRC, Boca Raton, FL

> Hart BT, Lake PS, Webb JA, Grace MR (2003) Assessing the risk of ecological impacts on aquatic systems from salinity. Aust J Bot 51:689-702

Hinshaw JM, Fornshall G (2002) Effluents from raceways. In: Tomasso JR (ed) Aquaculture and the environment in the United States. US Aquacultural Society, Baton Rouge, LA, p 77-104

Hurd TM, Jesic S, Jerin JL, Fuller NW, Miller D (2008) Stable isotope tracing of trout hatchery carbon to sediments and foodwebs of limestone spring creeks. Sci Total Environ 405:161-172

Kirkagac MU, Pulatsu S, Koksal G (2004) Effects of landbased trout farms on the benthic macroinvertebrate com-

Editorial responsibility: Ioannis Karakassis,

Heraklion, Greece munity in a Turkish brook. Isr J Aquacult Bamidgeh 56: $59-67$

Kruskal JB, Wish M (1978) Multidimensional scaling. Sage Publications, Beverly Hills, CA

Ladson AR, White LJ, Doolan JA, Finlayson BL, Hart BT, Lake PS, Tilleard JW (1999) Development and testing of an index of stream condition for waterway management in Australia. Freshw Biol 41:453-468

> Loch DD, West JL, Perlmutter DG (1996) The effect of trout farm effluent on the taxa richness of benthic macroinvertebrates. Aquaculture 147:37-55

Lunn DJ, Thomas A, Best N, Spiegelhalter D (2000) Winbugs - a Bayesian modelling framework: concepts, structure, and extensibility. Stat Comput 10:325-337

MacMillan JR, Huddleston T, Woolley M, Fothergill K (2003) Best management practice development to minimize environmental impact from large flow-through trout farms. Aquaculture 226:91-99

Metzeling L, Wells F, Newall P, Tiller D, Reid J (2004) Biological objectives for rivers and streams-ecosystem protection. Publication 793.2. Environment Protection Authority Victoria, Melbourne. Available at http:// tinyurl.com/EPA-793-2 (accessed on 1 September 2012)

> Oberdorff T, Porcher JP (1994) An index of biotic integrity to assess biological impacts of salmonid farm effluents on receiving waters. Aquaculture 119:219-235

Rasmussen G (1986) Influence of trout farm discharge on the production of two populations of stream dwelling brown trout Salmo trutta l. and rainbow trout Salmo gairdneri Rich. Pol Arch Hydrobiol 33:433-453

> Rennert B (1994) Water pollution by a land-based trout farm. J Appl Ichthyol 10:373-378

> Roberts L, Boardman G, Voshell R (2009) Benthic macroinvertebrate susceptibility to trout farm effluents. Water Environ Res 81:150-159

Rosenberg DM, Resh VH (eds) (1993) Freshwater biomonitoring and benthic macroinvertebrates. Chapman \& Hall, New York, NY

Selong JH, Helfrich LA (1998) Impacts of trout culture effluent on water quality and biotic communities in Virginia headwater streams. Prog Fish-Cult 60:247-262

Sindilariu PD (2007) Reduction in effluent nutrient loads from flow-through facilities for trout production: a review. Aquacult Res 38:1005-1036

Sindilariu PD, Reiter R, Wedekind H (2009) Impact of trout aquaculture on water quality and farm effluent treatment options. Aquat Living Resour 22:93-103

Storey AW, Edward DHD, Gazey P (1991) Surber and kick sampling: a comparison for the assessment of macroinvertebrate community structure in streams of southwestern Australia. Hydrobiologia 211:111-121

> Tello A, Corner RA, Telfer TC (2010) How do land-based salmonid farms affect stream ecology? Environ Pollut 158: 1147-1158

Villanueva VD, Queimalinos C, Modenutti B, Ayala J (2000) Effects of fish farm effluents on the periphyton of an Andean stream. Arch Fish Mar Res 48:283-294

- Webb JA, King EL (2009) A Bayesian hierarchical trend analysis finds strong evidence for large-scale temporal declines in stream ecological condition around Melbourne, Australia. Ecography 32:215-225

Webb JA, Stewardson MJ, Koster WM (2010) Detecting ecological responses to flow variation using Bayesian hierarchical models. Freshw Biol 55:108-126

Weston DP, Phillips MJ, Kelly LA (1996) Environmental impacts of salmonid culture. In: Pennell W, Barton BA (eds) Developments in aquaculture and fisheries science, Vol 29. Elsevier, Amsterdam, p 919-967

Submitted: March 23, 2012; Accepted: September 3, 2012

Proofs received from author(s): October 21, 2012 